\title{
Influence of Uranium, Thorium, and Zirconium Matrices on Silver Absorbance in Graphite Furnace Atomic Spectrometry (GFAAS)
}

\author{
Paru J. Purohit*, Neelam Goyal, and S.V. Godbole \\ Radiochemistry Division, Bhabha Atomic Research Centre, \\ Trombay, Mumbai 400 085, India
}

\begin{abstract}
The present studies were taken up to understand the influence of uranium, thorium, and zirconium matrices on silver absorbance in graphite furnace atomic absorption spectrometry (GFAAS). The absorbance signal of $\mathrm{Ag}$ in the presence of uranium (U), thorium (Th), and zirconium (Zr) matrices is significantly reduced compared to that in a matrix-free solution. To understand the effect of matrix on the Ag absorbance signal, the atomization mechanism of $\mathrm{Ag}$ was studied in the aqueous, $\mathrm{U}, \mathrm{Th}$, and $\mathrm{Zr}$ matrices. In aqueous, $\mathrm{U}$, and Th matrices, carbothermic reduction of $\mathrm{Ag}_{2} \mathrm{O}$ is followed by the vaporization of $\mathrm{Ag}_{(\mathrm{I})}$ at a lower temperature, while at a higher temperature the Ag trimer is the precursor to free atoms. In a $\mathrm{Zr}$ matrix, at low temperature, $\mathrm{Ag}$ atoms are formed by dissociation of gaseous silver fluoride $\left[\mathrm{AgF}_{(\mathrm{g})}\right]$, while at a higher temper-
\end{abstract}

ature mode of atomization it is the dissociation of the $\mathrm{Ag}$ dimer. Formation of $\mathrm{AgF}$ in a $\mathrm{Zr}$ matrix is due to the presence of fluoride ions which result from the $\mathrm{HF}$ solution used in the $\mathrm{Zr}$ matrix dissolution. The activation energies and the mode of atomization do not change in aqueous, uranium, and thorium matrices, while in a $\mathrm{Zr}$ matrix it changes due to the presence of fluoride ions. Signal appearance temperature increases in the matrix compared to matrix-free solution.

Reduction in the absorbance signal in the presence of the matrix was correlated to the possibility of physical trapping of the analyte in the stable matrix lattices, increased partial pressure of oxygen in the furnace, reduced active carbon sites, formation of inter-metallic compounds in case of a Th matrix and, to a lesser extent, due to tube deterioration with high matrix loading.

\section{INTRODUCTION}

Atomic absorption spectrometry (AAS) is one of the important techniques used in all analytical laboratories working on trace metallic assays of various materials. The strong point in favor of AAS, in particular with an electrothermal atomizer (ETA), is its ability to provide precise results and high sensitivity, and requiring only a significantly

*Corresponding autbor.

E-mail: parupurobit@yaboo.co.uk small sample size. ETA-AAS makes use of metal, graphite, and many other types of atomizers (1). ETAAAS with a graphite furnace (GF) atomizer suffers physical, chemical, and ionization interferences, which includes loss of volatile elements, reduced analyte volatility in the presence of the matrix, and/or a tendency for carbide formation $(1,2)$. In particular, these types of interference studies are done for geological (3) and biological samples $(4,5)$. The signal reduction in the majority of cases was identified as losses during the pre-atomization stage resulting from the formation of volatile compounds $(2,6)$. However, it is reported that chemical modifiers can be useful to overcome such problems (2). Recently, Peter et al. (7) effectively used in situ matrix separation for the determination of a few analytes in soil samples. In our laboratory, we developed analytical methods using a graphite furnace atomizer for a number of common metallic elements in nuclear materials such as plutonium (Pu) (8), uranium (U) (9), thorium (Th) $(10,11)$, and $\mathrm{Zr}$ (12), where the matrix is found to affect analyte absorbance.

During the development of these analytical procedures it was observed that for most of the elements, the absorbance signal was significantly reduced in the presence of $U$, Th, and $\mathrm{Zr}$ (8-12) matrices as compared to matrix-free solutions. Uranium, thorium, and zirconium are known to form refractory oxides and/or carbides and their effect on these analytes is not yet fully understood. Silver absorbance was also reduced significantly in the presence of these matrices. The present studies are, therefore, aimed at trying to understand the suppression in silver absorbance in the presence of these matrices and whether the atomization mechanism plays a role in absorbance suppression or if any other factors are responsible for the suppression in the absorbance signal.

A number of reports are available on the investigation of the atomization mechanism in aqueous solutions using various approaches, such as the kinetic (13), thermodynamic (14), and combined kineticthermodynamic approach (15). 
Also, by measuring the partial pressure of oxygen $(16,17)$ and through adsorption-desorption of the analyte from the atomizer surface (18, 19), the atomization mechanism of the particular analyte can be studied. In the present studies, we adopted the combined kineticthermodynamic approach to understand the atomization mechanism. The studies include the determination of signal appearance temperature $\left(\mathrm{T}_{\mathrm{app}}\right)$ and activation energy $\left(E_{a}\right)$ for atom formation in all of the matrices.

\section{EXPERIMENTAL}

\section{Instrumentation}

A Model GBC 906 atomic absorption spectrometer (GBC Scientific Equipment, Australia ), equipped with a GF-3000 power supply, GF-3000 graphite furnace atomizer, and deuterium lamp background correction system, was used for analyte atomization. Details of the AAS instrument and preparation of the $\mathrm{U}$ and $\mathrm{Th}$ matrix solutions are reported earlier $(20,21)$.

\section{Chemicals and Solution Preparations}

Uranium and thorium concentrations in the standard solution were $20 \mathrm{mg} / \mathrm{mL}$. High purity Ag solution (1 $\mathrm{mg} / \mathrm{mL}$ ) was procured from $\mathrm{E}$. Merck, Darmstadt, Germany. A zir- conium matrix solution was prepared by dissolving zirconium oxide (189 mg) in concentrated hydrofluoric acid in a platinum crucible and evaporating to dryness. Zirconium fluoride $\left(\mathrm{ZrF}_{4}\right)$ thus formed was dissolved in $2 \mathrm{~mL}$ of water and finally made up to $10-\mathrm{mL}$ volume with $0.1 \mathrm{M} \mathrm{HNO}_{3}$. Due to the poor solubility of $\mathrm{ZrF}_{4}(14 \mathrm{mg} / \mathrm{mL})$ (22), the $\mathrm{Zr}$ concentration in the standard solution was $10 \mathrm{mg} / \mathrm{mL}$. A Model M/s Raytek two-color optical pyrometer (Raytek Corporation, USA), sensitive in the range of 1000$3000{ }^{\circ} \mathrm{C}$, was used to measure the temperatures in the atomization stage.

\section{Procedure}

The detailed analytical procedure adopted in our laboratory for the determination of $\mathrm{Ag}$ in $\mathrm{U}$, Th, and $\mathrm{Zr}$ matrices was reported earlier (9-12). The heating parameters, optimized for Ag in the aqueous as well as $\mathrm{U} / \mathrm{Th} / \mathrm{Zr}$ matrices to ensure complete atomization so that the absorbance profile reaches to the base line, are listed in Table I. A cleaning step was introduced to ensure that there is no memory effect. During the optimization it was also ensured that there is no pre-atomization loss of an analyte. The absorbance signals for Ag in uranium at different pre-atomization temperatures are listed in Table II.
The activation energies and appearance temperatures for the atomization mechanism were determined from the Arrhenius plots of ln (A) vs. absolute $\mathrm{T}^{-1}$. Arrhenius plots were obtained from the absorbance-time-temperature profile of the absorbance signal. The slope of the plot is equal to $-\mathrm{E}_{\mathrm{a}} / \mathrm{R}$, where $\mathrm{E}_{\mathrm{a}}$ is the activation energy (15). These values were compared with the reported thermodynamic data and used to understand the mechanism. The graphite furnace temperatures were measured by focusing the optical pyrometer through the sampling hole, assuming that the black body conditions persisted. The set and measured temperatures were in good agreement. All absorbance measurements were carried out in peak height mode, which is the most commonly used signal measurement in analytical AAS since it provides better sensitivity. Walter Slavin (23) recommended the use of the platform technique for peak area measurements in GFAAS analysis. However, Slavin also mentioned that peak area measurements are not suitable where analytes are vaporized from the furnace wall. During the present work, the analyte was vaporized from the furnace wall; hence, the measurements were carried out in peak height mode.

\section{TABLE I} Atomization Temperatures for Ag in Aqueous, $\mathrm{U}$, Th, and $\mathrm{Zr}$ Matrices

\begin{tabular}{cccccc}
\hline \multicolumn{3}{c}{ Aqueous Solution } & \multicolumn{3}{c}{ U/ Th/ Zr Matrices } \\
$\begin{array}{c}\text { Tem- } \\
\text { perature } \\
\text { (K) }\end{array}$ & $\begin{array}{c}\text { Ramp } \\
\text { Time } \\
\text { (s) }\end{array}$ & $\begin{array}{c}\text { Hold } \\
\text { Time } \\
\text { (s) }\end{array}$ & $\begin{array}{c}\text { Tem- } \\
\text { perature } \\
(\mathrm{K})\end{array}$ & $\begin{array}{c}\text { Ramp } \\
\text { Time } \\
(\mathrm{s})\end{array}$ & $\begin{array}{c}\text { Hold } \\
\text { Time } \\
(\mathrm{s})\end{array}$ \\
\hline 253 & 10 & 15 & 253 & 10 & 15 \\
453 & 10 & 15 & 453 & 10 & 15 \\
573 & 10 & 15 & 573 & 10 & 15 \\
2473 & 1.0 & 0.3 & 973 & 2 & 30 \\
2573 & 0.1 & 0.2 & 2573 & 0.8 & 0.3 \\
& & & 2673 & 0.1 & 0.2 \\
\hline
\end{tabular}

TABLE II

Effect of Pre-atomization Temperature on Ag Absorbance in U Matrix (atomization temperature : $2573 \mathrm{~K}$ )

\begin{tabular}{lccccc}
\hline $\begin{array}{c}\text { Pre-atom. } \\
\text { Temp.(K) }\end{array}$ & $\begin{array}{c}\text { Ag } \\
\text { Absorb. }^{\mathrm{a}}\end{array}$ & $\begin{array}{c}\text { RSD } \\
(\%)\end{array}$ & $\begin{array}{c}\text { Blank } \\
\text { Absorb. }\end{array}$ & $\begin{array}{c}\text { RSD } \\
(\%)\end{array}$ & $\begin{array}{c}\text { Net } \\
\text { Absorb. }^{\mathrm{a}}\end{array}$ \\
\hline 573 & 0.399 & 36 & 0.110 & 15.0 & 0.289 \\
673 & 0.386 & 40 & 0.088 & 14.6 & 0.298 \\
773 & 0.385 & 23 & 0.084 & 14.0 & 0.301 \\
873 & 0.316 & 8.0 & 0.065 & 17.0 & 0.241 \\
973 & 0.255 & 2.9 & 0.050 & 4.0 & 0.205 \\
1073 & 0.217 & 2.4 & 0.046 & 3.0 & 0.171 \\
\hline
\end{tabular}

${ }^{\mathrm{a}}$ Absorb. = Absorbance. 


\section{RESULTS AND DISCUSSION}

During the development of analytical methods for a number of elements, it was found that the absorbance signals for the analytes in $\mathrm{U} / \mathrm{Th} / \mathrm{Zr}$ matrices were significantly reduced in comparion to those in aqueous solution (9-12). In the present studies, during optimization care was taken to ensure that there is no pre-atomization loss of Ag (Table II). As can be seen, with an increase in pre-atomization temperature the absorbance signal increased with an increase in blank contribution. Though the net absorbance was high at a lower preatomization temperature, the blank absorbance also increased with poor reproducibility. This is probably due to the incomplete decomposition of the matrix at temperatures lower than 973K. A similar trend was observed in the Th and $\mathrm{Zr}$ matrices. Therefore, in further studies, the pre-atomization temperature used was $973 \mathrm{~K}$. This also indicates that there are no preatomization losses and suppression in absorbance could be due to the presence of the matrix.

To understand the matrix suppression effect, the absorbance signal for $\mathrm{Ag}(0.04 \mu \mathrm{g} / \mathrm{mL})$ was measured in uranium for a repeated number of atomization cycles and compared with the signal obtained in aqueous solution. Figure 1 shows the absorbance signals obtained for $\mathrm{Ag}$ in aqueous solution in the first atomization cycle and subsequent signals in uranium matrix. There is a significant suppression even in the first loading of the U matrix. In subsequent loadings, the signal was reduced further and obtained nearly a constant/stable value after 8 to 12 atomizations. A similar effect was observed for other matrices. The suppression in the first loading of the matrix suggests that suppression occurs due to the presence of the matrix rather than due to a change such as deterioration of the atomizer surface.

The typical absorbance profile for Ag in all of the matrices is shown in Figure 2. Due to signal broadening in the $\mathrm{U} / \mathrm{Th} / \mathrm{Zr}$ matrices, the absorbance signals were measured both in peak height (maximum absorbance) and peak area mode (integrated absorbance from peak start to peak end) after 10 atomization cycles; i.e., after the absorbance signal has stabilized. An increase in peak width can be attributed to slow analyte release and, in such cases, peak area is a better mode of measurement. With this in view, the absorbances were measured both in peak height and peak area mode and are listed in Table III. It can be seen that the absorbance was reduced even in peak area mode, suggesting that the suppression is not only due to a slow release of analyte affecting peak height absorbance, but there is a net signal reduction which is reflected in peak area mode also. This indicates that the matrix plays a major role in signal suppression. To understand the change in atomization efficiency, the reaction mechanism was studied in the presence and absence of these matrices.

TABLE III

Absorbance Values for Ag in Peak Height and Peak Area Mode

\begin{tabular}{lcccc}
\hline Absorbance & Aqueous & Uranium & Thorium & Zirconium \\
\hline Peak Height (A) & 0.664 & 0.315 & 0.196 & 0.460 \\
Peak Area (A.s) & 0.156 & 0.138 & 0.059 & 0.116 \\
\hline
\end{tabular}

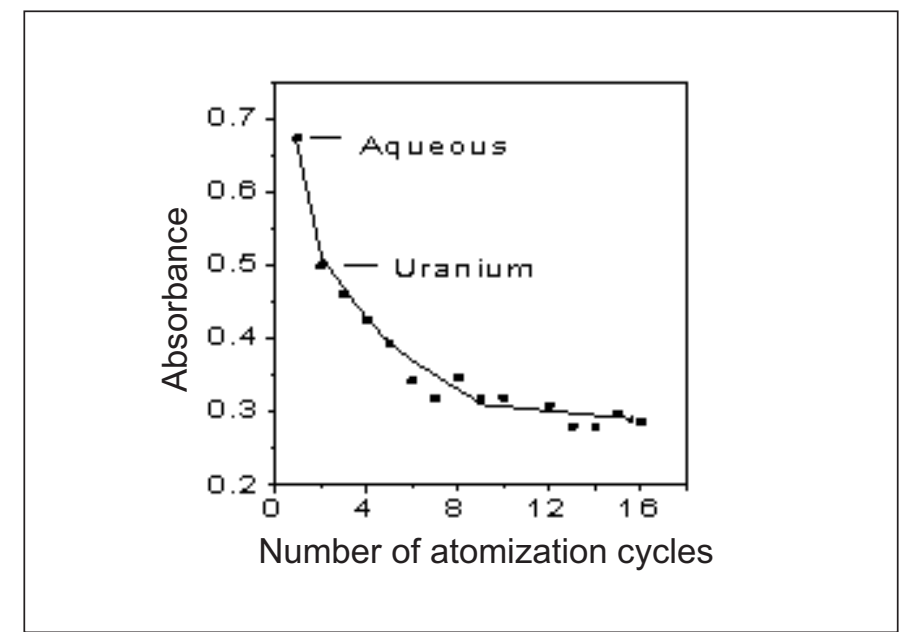

Fig. 1. Suppression in absorbance signal in presence of matrix (uranium). First absorbance: aqueous solution, subsequent absorbance: $U$.

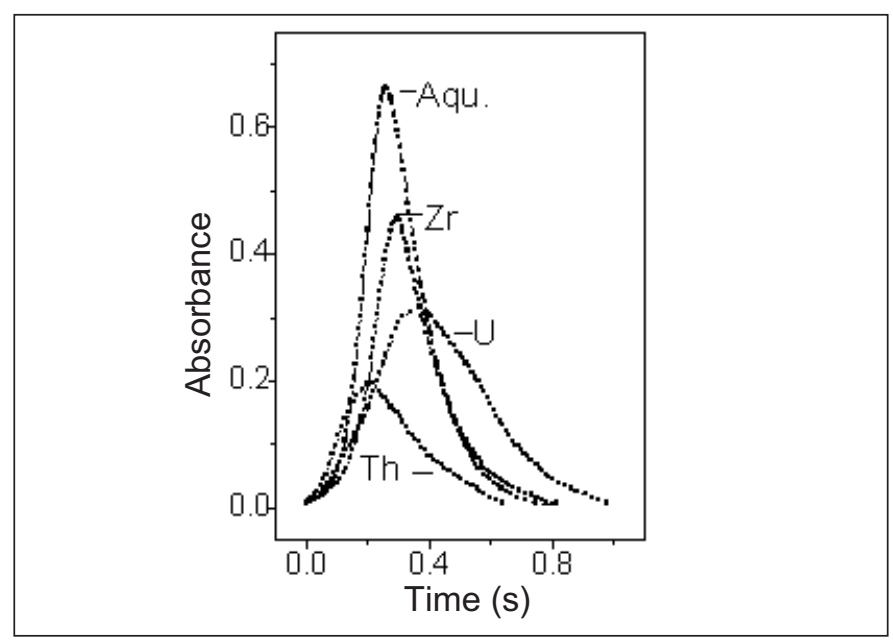

Fig. 2. Absorbance profile for Ag in aqueous, uranium, thorium, and zirconium matrices from peak ${ }_{a p p}$ to peak $k_{\text {end }}$. 


\section{Atomization Mechanism of Ag From Aqueous-Nitrate Solution}

The atomization temperature for $\mathrm{Ag}$ in aqueous solution is $2473 \mathrm{~K}$, while in $\mathrm{U}$, Th, and $\mathrm{Zr}$ it is $2573 \mathrm{~K}$. The sample is loaded in the form of $\mathrm{AgNO}_{3}$. Decomposition of $\mathrm{AgNO}_{3}$ is reported to take place as follows $(16,22,24)$ :

$$
\begin{array}{cr}
\stackrel{573 \mathrm{~K}}{\text { Eq. 1a }} \\
2 \mathrm{AgNO}_{3} \rightarrow \mathrm{Ag}_{2} \mathrm{O}_{(\mathrm{s})}+2 \mathrm{NO}_{2(\mathrm{~g})}+1 / 2 \mathrm{O}_{2}
\end{array}
$$

The Ag metal (condensed) is likely to be formed by dissociation of solid silver oxide at around $673 \mathrm{~K}$, much below the appearance temperature (1208K) of Ag. L'Vov (16) measured the partial pressure of oxygen and reported the dissociation of $\mathrm{Ag}_{2} \mathrm{O}$ into $\mathrm{Ag}$ atoms and $\mathrm{O}_{2}$ molecules. Aggett and Sprott (25) measured the vapor pressure of Ag from Ta ribbon and graphite filament atomizers. The minimum vaporization temperature of $\mathrm{Ag}$, from both atomizers, was the same with the vapor pressure of $1.33 \times 10^{-2} \mathrm{~Pa}$. These reports indicated that oxide dissociation precedes atomization.

Campbell and Ottaway (14) predicted that metal atoms are formed directly in the gaseous state following carbothermic reduction of the oxide. However, Frech et al. (26) reported the volatilization of condensed Ag, where the reduction step precedes volatilization. The $\mathrm{T}_{\mathrm{app}}(1208 \mathrm{~K})$ and $\mathrm{E}_{\mathrm{a}}$ obtained in the present work, along with the data from the literature in aqueous solutions, are listed in Table IV. In most of the cases, the single $\mathrm{E}_{\mathrm{a}}$ value (nearly $260 \pm 25 \mathrm{KJ} / \mathrm{mole}$ ) suggests the sublimation/vaporization of $\mathrm{Ag}_{(\mathrm{s} / \mathrm{l})}$; while Buhay et al. (19) and Rojas et al. $(18,27)$ obtained two $\mathrm{E}_{\mathrm{a}}$ values: vaporization/sublimation of Ag metal at lower temperature and cluster dissociation at higher temperature.

TABLE IV

$T_{\text {app }}$ and $E_{a}$ Values for Ag in Aqueous Medium: Obtained in Present Studies Compared With Those Reported in Literature

\begin{tabular}{llllllll}
\hline $\begin{array}{l}\text { Sr. } \\
\text { No. }\end{array}$ & $\begin{array}{c}\mathrm{T}_{\mathrm{app}} \\
(\mathrm{K})\end{array}$ & $\begin{array}{c}\mathrm{E}_{\mathrm{a}} \\
(\mathrm{KJ} / \mathrm{mole})\end{array}$ & $\begin{array}{c}\text { Ref. } \\
\text { No. }\end{array}$ & $\begin{array}{l}\text { Sr. } \\
\text { No. }\end{array}$ & $\begin{array}{c}\mathrm{T}_{\mathrm{app}} \\
(\mathrm{K})\end{array}$ & $\begin{array}{c}\mathrm{E}_{\mathrm{a}} \\
(\mathrm{KJ} / \mathrm{mole})\end{array}$ & $\begin{array}{l}\text { Ref. } \\
\text { No. }\end{array}$ \\
\hline 1 & 1150 & - & 14 & $8^{\mathrm{a}}$ & - & $237 / 124$ & 26 \\
2 & 1130 & 255 & 17 & 9 & - & 292 & 28 \\
$3^{\mathrm{a}}$ & - & $239 / 125$ & 18 & 10 & - & 250 & 29 \\
4 & - & 220 & 19 & 11 & 1053 & 252 & 30 \\
5 & - & 252 & 22 & 12 & 1120 & 269 & 31 \\
6 & 1123 & - & 24 & 13 & 1050 & 272 & $32 / 17$ \\
7 & 1050 & - & 25 & $14^{\mathrm{a}}$ & 1208 & $244 / 119$ & Present \\
\hline
\end{tabular}

*Two precursor mechanism.

There are a number of publications dealing with the thermodynamics and kinetics of thermal decomposition of $\mathrm{Ag}_{2} \mathrm{O}$, yet the real mechanism of $\mathrm{Ag}_{2} \mathrm{O}$ decomposition has not been fully established. However, prior to atomization, the presence of condensed silver in the furnace is reported by a number of researchers $(17,18,26-33)$. Free energy changes for oxide dissociation and carbothermic reduction of silver oxide (34) (at the temperatures where reaction becomes spontaneous) are shown below:

Eq. $2 a$

$$
\begin{aligned}
& \mathrm{Ag}_{2} \mathrm{O}_{(\mathrm{s})} \rightarrow 2 \mathrm{Ag}_{(\mathrm{s})}+0.5 \mathrm{O}_{2(\mathrm{~g})} \\
& \Delta \mathrm{G}^{\circ}{ }_{(\mathrm{R}) 500}=-1.9
\end{aligned}
$$

Eq. $2 \mathbf{b}$

$$
\begin{aligned}
& \mathrm{Ag}_{2} \mathrm{O}_{(\mathrm{s})}+\mathrm{C}_{(\mathrm{s})} \rightarrow 2 \mathrm{Ag}_{(\mathrm{s})}+\mathrm{CO}_{(\mathrm{g})} \\
& \Delta \mathrm{G}^{\circ}{ }_{(\mathrm{R}) 298}=-125.884
\end{aligned}
$$

Negative $\Delta G^{\circ}$ suggests that both reactions $(2 \mathrm{a}, 2 \mathrm{~b})$ are spontaneous. However, $\Delta \mathrm{G}^{\circ}$ for carbothermic reduction reaction takes place at a much lower temperature than oxide dissociation; carbothermic reduction of $\mathrm{Ag}_{2} \mathrm{O}$ looks more favorable and leads to the formation of Ag metal.

At appearance temperature (1208K), $\mathrm{Ag}$ is in $\mathrm{Ag}_{(\mathrm{l})}$ form. The melting point of $\mathrm{Ag}$ is $1233 \mathrm{~K}$. The Arrhenius plot for silver in aqueous solution in the present studies is shown in Figure 3a. Two intersecting segments indicate that two mechanisms are involved in the formation of free atoms. The temperature of intersection is $1323 \mathrm{~K}$. $\mathrm{E}_{\mathrm{a}}, 244 \mathrm{KJ} / \mathrm{mole}$, is in agreement with the heat of vaporization (22) of $\mathrm{Ag}$ at low temperature, while $\mathrm{E}_{\mathrm{a}}$, $119 \mathrm{KJ} / \mathrm{mole}$, agrees well with the dissociation of the trimer $\left[\mathrm{Ag}_{3(\mathrm{~g})}\right]$ $(35,36)$ at higher temperature. With an increase in temperature, Ag clusters are formed which are dissociated to Ag atoms at a higher temperature. The cluster is identified as trimer $\left[\mathrm{Ag}_{3(\mathrm{~g})}\right]$ on the basis of its dissociation energy. The atomization mechanism proposed in aqueous solution is the vaporization of $\mathrm{Ag}_{(\mathrm{l})}$ at lower temperature, while dissociation of $\mathrm{Ag}_{3(\mathrm{~g})}$ at higher temperature is preceded by carbothermic reduction of the oxide.

$$
\begin{aligned}
& 244 \mathrm{KJ} / \mathrm{mole} \\
& \operatorname{Ag}_{(\mathrm{I})} \quad \rightarrow \quad \operatorname{Ag}_{(\mathrm{g})} \\
& \text { Lower temperature }<1323 \mathrm{~K} \\
& \text { Eq. 3b } \\
& \mathrm{Ag}_{(\mathrm{I})} \rightarrow \underset{\mathrm{Ag}_{3(\mathrm{~g})}}{119 \mathrm{KJ} / \mathrm{mole}} \rightarrow \underset{\mathrm{Ag}_{(\mathrm{g})}}{\rightarrow} \\
& \text { Higher temperature }>1323 \mathrm{~K}
\end{aligned}
$$

It was rather strange to observe that the Ag absorbance increased with xylene treatment even with a new/fresh atomizer. However, xylene loading prior to atomization is helpful in preventing seepage losses due to prolonged use of the 
atomizer. The average of five absorbance values was obtained from the new atomizer with and without use of xylene prior to sample loading (see Table V). Signal intensity was improved by $60 \%$ in the aqueous matrix, while $20-30 \%$ in the $U$ and $T h$ matrices with the use of xylene prior to sample loading. This can probably be attributed to a higher number of active carbon sites due to xylene loading, which in turn helps to increase the carbothermic reduction process and effectively improves signal intensity. This further confirms that in the aqueous, $\mathrm{U}$, and Th matrices, carbothermic reduction plays a predominant role prior to the formation of $\mathrm{Ag}$ atoms.

\section{Atomization Mechanism of Ag From U, Th and Zr Matrices}

$E_{a}$ plots for silver in all of the matrices are shown in Figures $3 a, b$, $\mathrm{c}$, and $\mathrm{d}$. The appearance temperature and activation energies deter- mined in the aqueous, $\mathrm{U}, \mathrm{Th}$, and $\mathrm{Zr}$ matrices are listed in Table VI. $\mathrm{E}_{\mathrm{a}}$ in the $\mathrm{U}$ and Th matrices are nearly the same as in aqueous solution. This indicates that there is no change in the atomization mechanism in the $\mathrm{U}$ and Th matrices. The $\mathrm{E}_{\mathrm{a}}$ values for $\mathrm{Ag}$ in the $\mathrm{Zr}$ matrix are higher compared to those obtained in the aqueous, $\mathrm{U}$, and Th matrices. This suggests that the atomization mechanism is quite different for the Zr matrix.

It is to be noted that the $\mathrm{Zr}$ solution contains both $\mathrm{NO}_{3}{ }^{-}$and $\mathrm{F}^{-}$ ions, suggesting the possible role of the fluoride ion during the atomization process. The heat of formation for $\mathrm{AgF}$ and $\mathrm{AgF}_{2}$ is -204.82 and $-51 \mathrm{KJ} / \mathrm{mole}$, respectively. Even though the formation of $\mathrm{AgF}_{2}$ is more favorable, it decomposes to $\mathrm{AgF}$ at $973 \mathrm{~K}$ and can be a likely precursor in the atomization process. The activation energy obtained at a lower temperature $(<1736 \mathrm{~K})$ is $369 \mathrm{KJ} / \mathrm{mole}$, which is in close agree- ment with the bond energy of $\operatorname{AgF}_{(g)}(22)$, while at a higher temperature $(>1736 \mathrm{~K}), \mathrm{E}_{\mathrm{a}} 151 \mathrm{KJ} / \mathrm{mole}$ matches well with the dimer (34) dissociation. In addition, the boiling point of $\mathrm{AgF}$ is $1435 \mathrm{~K}$, while $\mathrm{T}_{\mathrm{app}}$ for $\mathrm{Ag}$ in the $\mathrm{Zr}$ matrix is $1550 \mathrm{~K}$, which supports that $\mathrm{AgF}$ is in gaseous form. Thus, the mode of atomization in $\mathrm{Zr}$ is dissociation of $\operatorname{AgF}_{(\mathrm{g})}$ at lower temperature, while at higher temperature dimer $\left[\mathrm{Ag}_{2(\mathrm{~g})}\right]$ dissociation is the preferred mode of atomization. Following is the reaction mechanism in the $\mathrm{Zr}$ matrix:

$$
\begin{aligned}
& \text { 1432K } \quad 369 \mathrm{KJ} / \mathrm{mole} \\
& \operatorname{AgF}_{(\mathrm{s})} \rightarrow \operatorname{AgF}_{(\mathrm{g})} \quad \rightarrow \quad \operatorname{Ag}_{(\mathrm{g})} \\
& \text { Lower temperature }<1736 \mathrm{~K} \\
& 151 \mathrm{KJ} / \mathrm{mole} \\
& \operatorname{AgF}_{(\mathrm{g})} \rightarrow \mathrm{Ag}_{2(\mathrm{~g})} \quad \rightarrow \quad \mathrm{Ag}_{(\mathrm{g})} \\
& \text { Higher temperature }>1736 \mathrm{~K}
\end{aligned}
$$

Higher $\mathrm{E}_{\mathrm{a}}$ in $\mathrm{Zr}$ corresponds to the smaller cluster size and increased cohesive forces of the atoms in the clusters. In the $\mathrm{Zr}$ matrix, xylene treatment was not significant as in this case fluoride dissociation is the mode of atomization.

\section{Signal Suppression in the Presence of Matrix}

$\mathrm{E}_{\mathrm{a}}$ in aqueous/U/Th matrices sug-

\begin{tabular}{|c|c|c|c|c|c|}
\hline \multirow[t]{2}{*}{ Matrix } & \multirow{2}{*}{$\begin{array}{l}\text { Atom. } \\
\text { Temp. (K) }\end{array}$} & \multirow{2}{*}{$\begin{array}{l}\mathrm{T}_{\text {app }} \\
(\mathrm{K})\end{array}$} & \multirow{2}{*}{$\begin{array}{c}\text { Inter- } \\
\text { section }(\mathrm{K})\end{array}$} & \multicolumn{2}{|c|}{ Activation Energy $E_{a}(K J / m o l e)$} \\
\hline & & & & Lower Temperature & Higher Temperature \\
\hline \multirow[t]{2}{*}{ Aqueous/Nitrate } & $2473 \mathrm{~K}$ & $1208 \pm 50$ & 1323 & $244 \pm 9$ & $110 \pm 12$ \\
\hline & & & & $\mathrm{Ag}_{(\mathrm{l})}$ vaporization & $\mathrm{Ag}_{3(\mathrm{~g})}$ dissociation \\
\hline \multirow[t]{2}{*}{ Uranyle Nitrate } & $2573 \mathrm{~K}$ & $1421 \pm 60$ & 1578 & $261 \pm 8$ & $110^{5}$ \\
\hline & & & & $\mathrm{Ag}_{(\mathrm{I})}$ vaporization & $\mathrm{Ag}_{3(\mathrm{~g})}$ dissociation \\
\hline \multirow[t]{2}{*}{ Thorium Nitrate } & $2573 K$ & $1390 \pm 60$ & 1530 & $273 \pm 8$ & $122 \pm 8$ \\
\hline & & & & $\mathrm{Ag}_{(\mathrm{l})}$ vaporization & $\mathrm{Ag}_{3(\mathrm{~g})}$ dissociation \\
\hline \multirow[t]{2}{*}{$\mathrm{Zr}\left(\mathrm{HF}+\mathrm{HNO}_{3}\right)$} & $2573 K$ & $1550 \pm 40$ & 1736 & $369 \pm 10$ & $151 \pm 8$ \\
\hline & & & & $\operatorname{AgF}_{(\mathrm{g})}$ dissociation & $\mathrm{Ag}_{2(\mathrm{~g})}$ dissociation \\
\hline
\end{tabular}
gests that the mode of atomization has remained the same and does

\begin{tabular}{lcccc}
\hline Atomization & Aqueous & Uranium & Thorium & Zirconium \\
\hline W/O Xylene & 0.359 & 0.471 & 0.281 & 0.419 \\
With $10 \mu \mathrm{L}$ Xylene & 0.579 & 0.526 & 0.372 & 0.428 \\
\hline
\end{tabular}

TABLE VI

$T_{a p p}$ and $E_{a}$ Values for $\mathrm{Ag}$ in Aqueous, $\mathrm{U}, \mathrm{Th}$, and $\mathrm{Zr}$ Matrices in Present Studies 
not explain the suppression in the absorbance signal in the presence of the matrix. The reduction in the absorbance is in the order

$\mathrm{Th}>\mathrm{U}>\mathrm{Zr}$. The most probable reasons for absorbance suppression, which can be applied to most of the oxide-containing matrices, are as follows:

\section{Reduced Active Carbon Sites}

Increased oxygen concentration (Eq. 5a, 6a) due to the decomposition of large matrix concentrations (compared to that in aqueous solution and formation of U/Th carbides, Eq. $5 b, 6 b)$ reduces the active carbon sites, affects the carbothermic reduction process, and in turn the atom density for the AA signal.

\section{Pbysical Trapping}

As seen from the absorbance profile, Th has maximum suppressive effect (70\%) compared to U (45\%) and $\mathrm{Zr}$ (25\%). The matrix concentration in the GF is $100 \mu \mathrm{g} /$ aliquot, while that of $\mathrm{Ag}$ is at nanogram level. It is likely that $\mathrm{Ag}$ atoms are physically trapped in the stable thoria-urania matrix lattice (10). The relatively lesser degree of suppression observed in the $\mathrm{Zr}$ matrix can probably be due to a smaller $(10 \mathrm{mg} / \mathrm{mL})$ amount of matrix used. Moreover, the average linear thermal expansion coefficient (37) for $\mathrm{ThO}_{2}\left(9.32 \times 10^{-6} \% / \mathrm{C}\right)$ is less than for $\mathrm{UO}_{2}\left(10.52 \times 10^{-6} / \mathrm{C}\right)$ in the temperature range of $298-1273 \mathrm{~K}$. Release of trapped atoms from the $\mathrm{ThO}_{2}$ matrix lattice will be much slower and more difficult than from the $\mathrm{UO}_{2}$ matrix lattice, causing larger suppression.

\section{Inter-metallic Compounds}

Formation of Ag-Th inter-metallic compounds (38) with eutectic temperatures less than or equal to the appearance temperature of $\mathrm{Ag}$, i.e., $\mathrm{ThAg}_{3}(1163 \mathrm{~K}), \mathrm{ThAg}_{2}(1178 \mathrm{~K})$, and $\mathrm{Th}_{2} \mathrm{Ag}(1230 \mathrm{~K})$, suggests that significant suppression in case of Th in the absorbance signal can also occur due to the formation of inter-
Eq. $5 a$

Thorium: $\stackrel{873 \mathrm{~K}}{\mathrm{Th}\left(\mathrm{NO}_{3}\right)_{4}} \cdot 4 \mathrm{H}_{2} \mathrm{O} \stackrel{1973 \mathrm{~K}}{\rightarrow} \mathrm{ThO}_{2(\mathrm{~s})} \stackrel{\rightarrow}{\rightarrow} \mathrm{ThO}_{(\mathrm{g}) \text { partially }}+0.5 \mathrm{O}_{2}$

Eq. $5 \mathbf{b}$
$\mathrm{ThO}_{2(\mathrm{~s})}+4 \mathrm{C}_{(\mathrm{s})} \stackrel{2413 \mathrm{~K}}{\rightarrow} \mathrm{ThC}_{2(\mathrm{~s})} 2 \mathrm{CO}$

Eq. 6a

Uranium:
\[ \mathrm{UO}_{2}\left(\mathrm{NO}_{3}\right)_{2} \cdot 6 \mathrm{H}_{2} \mathrm{O} \stackrel{650 \mathrm{~K}}{\rightarrow} \mathrm{U}_{3} \mathrm{O}_{8(\mathrm{~s})} \stackrel{1373 \mathrm{~K}}{\rightarrow} \mathrm{UO}_{3(\mathrm{~s})} \rightarrow \mathrm{UO}_{2(\mathrm{~s})}+0.5 \mathrm{O}_{2} \]

Eq. $6 \mathbf{b}$

$$
\mathrm{UO}_{2}+4 \mathrm{C}_{(\mathrm{s})} \stackrel{1973 \mathrm{~K}}{\rightarrow} \mathrm{UC}_{2(\mathrm{~s})}+2 \mathrm{CO}
$$
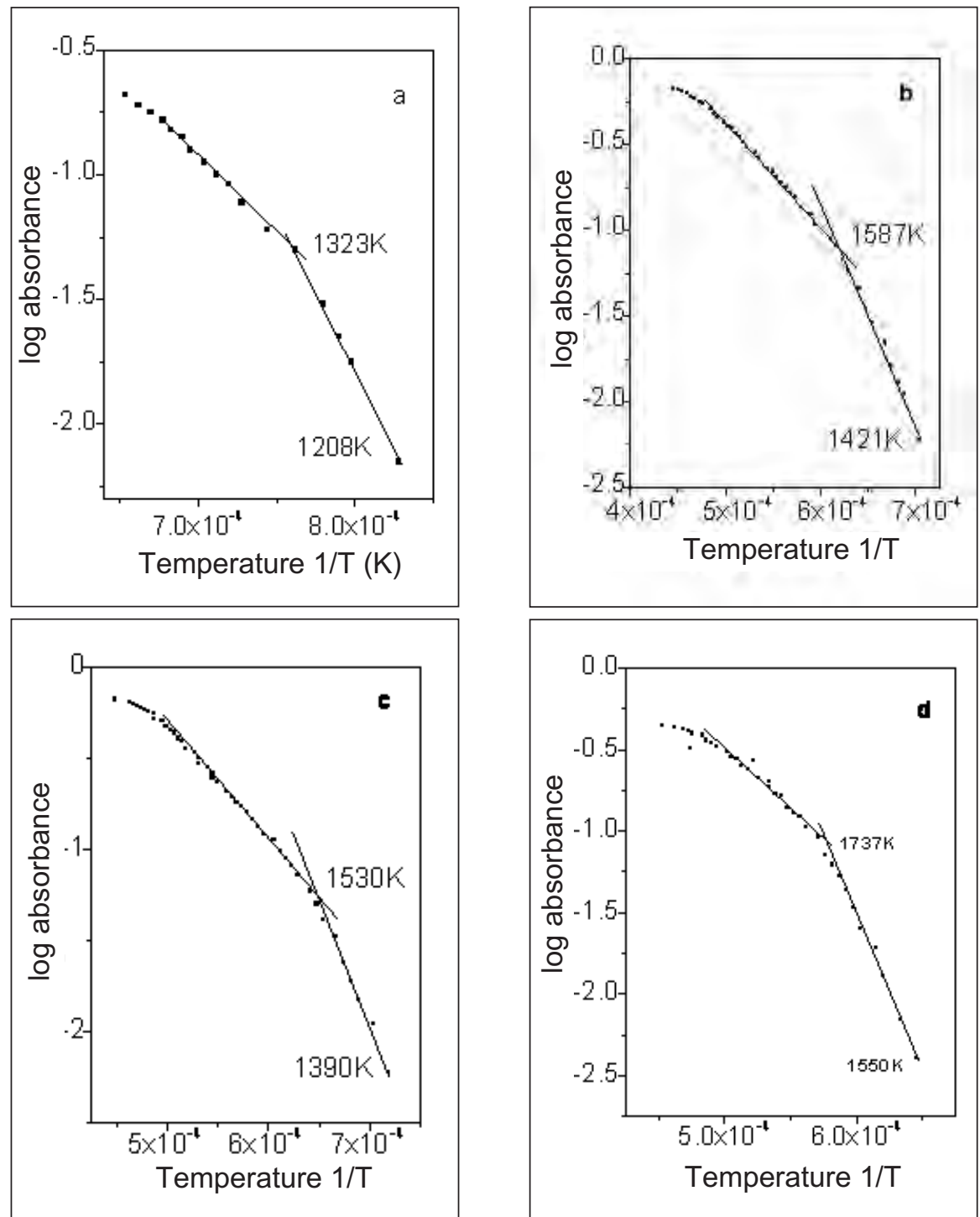

Fig. 3. $E_{a}$ plots for Ag in different matrices (a) aqueous, (b) uranium, (c) thorium, (d) zirconium. 
metallic compounds. $\mathrm{U}$ and $\mathrm{Zr}$ do not form an inter-metallic compound with silver.

\section{Furnace Deterioration}

Suppression of the absorbance signal due to deterioration of the graphite furnace cannot be ruled out (39). The atomizer surface is affected due to carbide formation and an increase in oxygen content, which leads to a reduction in active carbon sites and is chemical in nature. On the other hand, the effect due to surface deterioration resulting from repeated use of the furnace for more than 50 atomization cycles leads to seepage losses of the sample and is physical in nature. The latter effect also leads to signal suppression but to a lesser extent and after a proplonged use of the atomizer. However, a signal suppression in the presence of the matrix right from the first atomization cycle indicates that suppression due to tube deterioration cannot be the major cause.

Thus, suppression in the absorbance signal of $\mathrm{U}$, Th, and $\mathrm{Zr}$ matrices is a composite effect of all the factors mentioned above and cannot be explained fully by any one of the effects. In the present studies, the signal appearance temperature in the $\mathrm{U}$, Th, $\mathrm{Zr}$ matrices is higher than from aqueous solution (Table VI). This can be due to increased partial pressure of oxygen $(17,40)$, which reduces the active carbon sites and shifts the absorbance signal to a higher temperature.

\section{CONCLUSION}

In this study, the effect of the presence of the matrix (U, Th, and $\mathrm{Zr}$ ) on Ag absorbance and its atomization mechanism was investigated using a graphite furnace atomizer. The atomization mechanism in aqueous/U/Th solutions is the vaporization of $\mathrm{Ag}_{(1)}$ at lower temperature, while dissociation of
$\mathrm{Ag}_{3(\mathrm{~g})}$ at higher temperature preceded by carbothermic reduction of the oxide. In case of a $\mathrm{Zr}$ matrix, the mode of atomization is dissociation of $\mathrm{AgF}_{(\mathrm{g})}$ at lower temperature, while at higher temperature dimer dissociation is the preferred mode of atomization. The atomization mechanism does not have any significant effect on signal absorbance. Suppression can probably be due to an increased partial pressure of oxygen and formation of stable matrix carbides, which reduces the active carbon sites affecting the carbothermic reduction and also physical trapping of the analyte in the stable matrix lattice. Though to a lesser extent, suppression due to tube deterioration cannot be ruled out. Formation of Ag-Th eutectoids in the thorium matrix causes relatively large suppression compared to $\mathrm{U} / \mathrm{Zr}$ matrices. No such compounds are reported in $\mathrm{U}$ and $\mathrm{Zr}$ matrices. This work is useful for laboratories working in the field of spectrochemical analysis of nuclear fuels.

\section{ACKNOWLEDGMENTS}

The authors sincerely thank Dr. A. Goswami, Head, Radiochemistry Division, for his keen interest and constant encouragement during the course of this work.

Received November 28, 2011.

\section{REFERENCES}

1. Jiří Dědina, Spectrochim. Acta 62B, 846 (2007).

2. D.L. Tsalev, V.I. Slaveykova and P.B. Mandjukov, Spectrochim. Acta Rev. 13, 225 (1990).

3. Chai Xin-na, Shuai Qin, LU Aimin,Yao Qiu-yue, Liu Xian-guo, Spectroscopy and Spectral Analysis 28, 1406 (2008) .

4. G. Yang, F. Weibo, Chun Lei, W. Xiao, and S. Handong, J. Hazardous Mat. 162, 44 (2009).
5. J. Sardans, F. Montes, and J. Peñuelas, Spectrochim. Acta 65B, 97 (2010).

6. J.Y. Cabon, Talanta 65, 402 (2005).

7. Peter Török and M. Žemberyová, Spectrochim. Acta 66B, 93 (2011).

8. Neelam Goyal, Renu Agarwal, Paru J. Purohit and S.V. Godbole, J. Nucl. Mat. 376119 (2008).

9. Neelam Goyal, P.J. Purohit, A.R. Dhobale, B.M. Patel, A.G. Page and M.D. Sastry, J. Anal. At. Spectrom. 2, 459 (1987).

10. Paru J. Purohit, Neelam Goyal and S.V. Godbole, At. Spectrosc. 32, 68 (2011).

11. S.K. Thulasidas, M.J. Kulkarni, N.K. Porwal, A.G. Page and M.D. Sastry, Anal. Lett. 21, 265 (1988).

12. Paru J. Purohit, Neelam Goyal, A.G. Page and M.D. Sastry, Indian Council of Chemists, held at Goa, India, during Oct. 1991, see pp. 202 (1991)

13. C.W. Fuller, Analyst 101, 798 (1976) .

14. W. C. Campbell and J.M. Ottaway, Talanta 21, 837 (1974).

15. R.E. Sturgeon, C.L. Chakrabarti, and C.H. Langford, Anal. Chem. 48, 1792 (1976).

16. B.V. L'vov, Thermochim. Acta 333, 13 (1999).

17. C. H. Chung, Anal. Chem. 56, 2714 (1984).

18. D. Rojas and W. Olivares, Spectrochim. Acta 50B, 1011 (1995).

19. O.M. Buhay, Yu.V. Rogulsky, A.N. Kulik, A.N. Kalinkevich, and L.F. Sukhodub, Spectrochim. Acta 60B, 491 (2005) and references therein.

20. Neelam Goyal, Paru J. Purohit, M.J. Kulkarni, and S.V. Godbole, At. Spectrosc. 30, 156 (2009).

21. Paru J. Purohit, N. Goyal and A.G. Page, At. Spectrosc. 26, 79 (2005).

22. Handbook of Chemistry and Physics, 55th, Ed. R.C. Weast, Chemical Rubber Co., Cleveland, $\mathrm{OH}$, USA (1975).

23. W. Slavin, Fresenius Z. Anal. Chem. 316, 319 (1983). 
24. Kurt H. Stern, J. Phy. and Chem. Ref. Data 1, 766 (1972).

25. J. Aggett and A.J. Sprott, Anal. Chim. Acta 72, 49 (1974).

26. W. Frech, E. Lundberg and A. Cedergren, Prog in Anal. At. Spectrosc. 8, 257 (1985).

27. D. Rojas, Spectrochim. Acta 50B, 1031 (1995).

28. S. Musil, Jan Kratzer, Miloslav Vobecký, Jan Hovorka, O. Benada, and T. Matoušek, Spectrochim. Acta 64B, 1240 (2009).

29. W. Frech, N.G. Zhou, and E. Lundberg, Spectrochim. Acta 37B, 691(1982).

30. B.V. L'vov, Spectrochim. Acta, 52B, 1 (1997).

31. B. Smets, Spectrochim. Acta 35B, 33 (1980).

32. S.G. Salmon and J.A. Holcombe, Anal Chem. 54, 630 (1982).

33. B.V. L'vov, P.A.Bayunov and G.N. Ryabchuk, Spectrochim. Acta 36B, 397 (1981).

34. G.V. Below and B.G. Trusov, in ASTD Computer Aided Reference Book in Thermodynamic, Thermochemical and Thermophysical Properties of Species, Version 2, Moscow, Russia (1983-1995).

35. M.D. Morse, Chem. Rev. 86, 1049 (1986).

36. E. Ganz, K. Sattler, and J. Clarke, Surface Science 219, 33 (1988), and references therein.

37. Charles P. Kempter and Reed O. Eliot, J. Chem. Physics 30, 1524 (1959).

38. J.C. Bailar et al., Comprehensive Inorganic Chemistry, Vol 5, Ist Ed., Edited by Trotman-Dickenson, Pargamon Press, Oxford, UK, pg. 105 (1973).

39 Yu.V. Rogul'Skii and A.N. Bugai, J. of Appl. Spectrosc. 71, 282 (2004).

40. R.E. Sturgeon and H. Falk, J. Anal. At. Spectrosc. 3, 27 (1988), and references therein. 